\title{
Biological Activities of Organometalloid (As, At, B, Ge, Si, Se, Te) Steroids
}

\author{
Valery M. Dembitsky $^{1 *}$, Tatyana A. Gloriozova ${ }^{2}$, Vladimir V. Poroikov ${ }^{2}$ \\ ${ }^{1}$ National Scientific Center of Marine Biology, Vladivostok, Russia. \\ ${ }^{2}$ Institute of Biomedical Chemistry, Moscow, Russia.
}

\begin{tabular}{|c|c|}
\hline ARTICLE INFO & ABSTRACT \\
\hline $\begin{array}{l}\text { Article history: } \\
\text { Received on: } 23 / 09 / 2017 \\
\text { Accepted on: } 09 / 11 / 2017 \\
\text { Available online: } 30 / 11 / 2017\end{array}$ & $\begin{array}{l}\text { Organometallic steroids (OS) represent an interesting class of biologically active hormones including anabolic } \\
\text { steroids. Currently, more than } 1,000 \text { OS have been synthesized, and many are widely used in medical practice, } \\
\text { including sports medicine and pharmacology. In this review, we present structures of OS that contain (along } \\
\text { with the composition of a molecule of metalloids) As, At, B, Ge, Si, Se, and Te. We also used an algorithm that }\end{array}$ \\
\hline $\begin{array}{l}\text { Key words: } \\
\text { Organometalloids, boronic } \\
\text { steroids, arsenosteroids, } \\
\text { astatosteroids, germylated } \\
\text { steroids, silasteroids, selena } \\
\text { steroids, tellura steroids, } \\
\text { activities. }\end{array}$ & $\begin{array}{l}8,000 \text { validated biological activities and allows you to calculate the predicted activity from the chemical } \\
\text { structure of the steroidal molecule. From the huge variety of steroidal structures, we selected more than } 100 \mathrm{OS} \\
\text { that belong to seven groups, including boronic steroids, arsenosteroids, astatosteroids, germylated steroids, } \\
\text { silasteroids, selena steroids and tellura steroids. The biological activity for these groups of OS is presented in } \\
\text { this paper. Additionally, it is important to note that these selena and tellura steroids showed a high anticancer } \\
\text { activity and they can be used as anti-parkinsonian, anti-Alzheimer's disease and anti-neurodegenerative agents. }\end{array}$ \\
\hline
\end{tabular}

\section{INTRODUCTION}

Bioorganometallic chemistry is an area at the intersection of many areas of science and the medicinal chemistry and pharmaceutical industry, and above all, medicine, pharmacology, organic and inorganic chemistry (Jaouen and Salmain, 2015). Steroids belong to the class of natural lipids, which are produced by microorganisms (Galán et al., 2017), plants (Valitova et al., 2016), animals (Guzman et al., 2017) and marine algae and invertebrates (Fiorucci et al., 2012; Zubair et $a l ., 2016)$. Steroids and their derivatives have a huge number of diverse structures and have a wide range of biological activities (Xu et al., 2004). Currently, more than 70,000 natural and

\footnotetext{
* Corresponding Author

Valery M. Dembitsky, Biochemistry Lab, National Scientific Center of Marine Biology, 17 Palchevsky Str., Vladivostok, Russia 690041; Tel: (7423) 2310905; Fax: (7423) 2310900;E-mail:valeryde @imb.dvo.ru
}

synthetic steroids and their derivatives are known. Organometalloid steroids (OS), or steroids containing semi-metals, are a unique class of chemical compounds that are not found in nature, and only synthesized molecules that have a huge variety of chemical structures are known (Chiusoli et al., 1979; Zeelen, 1994; Ehrenstein 1948; Omar et al., 2008). OS are widely used in research and the medical and pharmaceutical industries (Charney and Herzog, 1967).

Concept organometallic steroids were introduced in the mid-1950s by a few groups of scientists (Thackray et al., 1985). Presently, approximately 1,000 synthetic OS and their derivatives are known at present time (Coogan and Dyson, 2012; Parshall, 1987).

We selected more than 100 stable OS, including anabolic steroids, which are interesting from the point of view of medicine and pharmacology and for the pharmaceutical industry (Jaouen and Salmain, 2015). Many OS show anti-tumour, antiviral and antibacterial activity (Fuentes-Aguilar et al., 2017). 
All of the steroids were separated on seven groups of steroids that represent: group one, boronic steroids; group two, arsenosteroids; group three, astatosteroids; group four, germylated steroids; group five, silasteroids; group six, selena steroids, and group seven, tellura steroids. We used the PASS computer programme that use the structure-activity relationship (SAR) algorithm to determine the relationship between chemical structure steroids and determines the biological activity of OS. This is the first attempt to determine the biological activity of synthetic OS containing various metalloid(s) in their structures. This review emphasizes the role of OS as an important source of leads for drug discovery, and they are of great interest to chemists, physicians, biologists, pharmacologists and the pharmaceutical industry.

\section{STRUCTURE ACTIVITY RELATIONSHIP FOR ORGANOMETALLOID STEROIDS}

The acronym PASS stands for Prediction of Activity Spectra for Substances (www.pharmaexpert.ru).The PASS software product, which predicts more than 8,000 pharmacological effects and biochemical mechanisms on the basis of the structural formula of a substance, may be efficiently used to find new targets (mechanisms) for some ligands and, conversely, to reveal new ligands for some biological targets. Upon entering a structural formula of a chemical substance, the program returns the potential biological activities of this compound. PASS has been well accepted by the community, and is now actively used in the field of medicinal chemistry, by both academic organizations and pharma companies. The PASS program can be used in the fields of: SAR (qualitative structure-activity relationship), medicinal chemistry, computational chemistry, drug discovery, drug repositioning, chemical toxicity, natural and synthetic compound effects. As already proved by numerous works, there is a relationship between structure and activity, and this principle is called SAR (Structure-Activity-Relationship). We used the computer program PASS, containing about one million chemical compounds and more than 8,000 biological activities, and calculated the biological activity of different natural and/or synthetic compounds (Levitsky et al., 2016; Dembitsky et al., 2017; Sergeiko et al., 2008). PASS predictions are based on SAR analysis of the training set consisting of more than one million drugs, drug candidates and lead compounds. The algorithm of PASS practical utilization is described in detail in several publications (Filz and Poroikov, 2012; Borodina et al., 2003; Lagunin et al., 2011). Synthetic OS were used to calculate their pharmacological activity. Using MOL or SD files as an input for
PASS program, the user may get a list of probable biological activities for any drug-like molecule as an output. For each activity, $\mathrm{P}_{\mathrm{a}}$ and $\mathrm{P}_{\mathrm{i}}$ values are calculated, which can be interpreted either as the probabilities of a molecule belonging to the classes of active and inactive compounds, respectively, or as the probabilities of the first and second kind of errors in prediction. A computer analysis of the predicted biological activity spectra showed that 263 types of biological activity are predicted with $\mathrm{Pa}>70 \%$ and 587 with $\mathrm{Pa}>50 \%$. In a biological activity spectrum estimated by PASS, the activity predicted with the highest probability is called the focal activity. Although the majority of the known biological activities for respective OS are associated with antineoplastic action, their number is less than $60 \%$ among the predicted focal activities.Confirmed activity is the activity found for this steroid and confirmed by the PASS system. The criteria for choosing synthetic OS containing various metalloid atom(s) are presented in our article. The first requirement when choosing an OS for the study of their biological activity using the PASS system is the chemical stability of steroids. For a comprehensive determination of the activity of the individual steroid metalloid, we used a fixed position of the metalloid atoms in the position of the steroid skeleton. So, different metalloids were incorporated mainly in position 3, 4, 6, 7, 11 and 16. Other metalloids were to a lesser extent in position 1, 2, 5, 20 and 24. Rare representatives of steroids containing metalloid atom in position $10,13,19$, and other positions (Tables 1, 2, 3, 4, 5, 6, and 7).

\section{BORONIC STEROIDS}

Organoboron chemistry is an area of organic and inorganic chemistry that studies the chemical compounds of boron and carbon (C-B or C-O-B). Organic compounds of boron, which are now include more than 100,000 compounds, have a wide spectrum of biological activities (Ali et al., 2005; Dembitsky et al., 2003, 2004). The medical chemistry of boron is an area of organic chemistry that studies the biological activity of organoboranes (Smoom et al., 2012; Dembitsky et al., 2011). Organic compounds of boron are devoted to a large number of excellent reviews and books.

They are also inhibitors of many enzymes and show antibacterial, anticancer and other activities (Smoom et al., 2012). We selected fifteen steroids that contain a boron atom. The main activities that are characteristic of boronic steroids are: antineoplastic, anti-eczematic, and anti-hypertensive properties and these steroids are apoptosis agonist agents. The other biological activity is shown in Table 1 .

Table 1: Predicted biological activities of boronic steroids (1-15)

\begin{tabular}{ll}
\hline Boronic steroids & Predicted activities (Pa)* \\
\hline Antieczematic $(0.804$ \\
Antihypertensive $(0.798))$ \\
Myocardial ischemia treatment $(0.751)$ Antineoplastic $(0.735)$ \\
Dermatologic $(0.716)$ \\
Bone diseases treatment $(0.703)$ \\
Antiosteoporotic $(0.681)$ \\
Immunosuppressant $(0.672)$ \\
Antipsoriatic $(0.665)$ \\
Prostate disorders treatment $(0.655)$
\end{tabular}



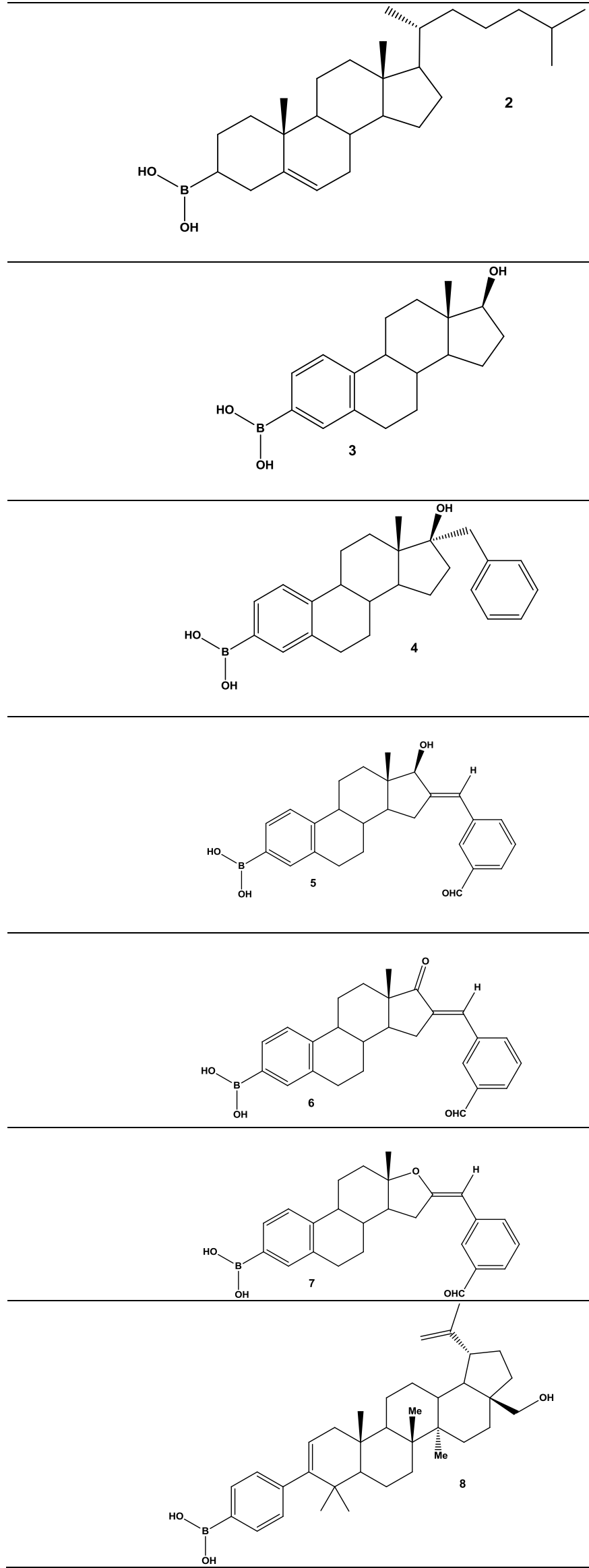

Antineoplastic (0.796)

Antieczematic (0.796)

Dermatologic (0.767)

Antihypercholesterolemic (0.756)

Bone diseases treatment $(0.749)$

Immunosuppressant (0.729)

Antiosteoporotic (0.717)

Prostate disorders treatment $(0.711)$

Antipruritic (0.708)

Antipsoriatic (0.703)

Myocardial ischemia treatment (0.692)

Antihypertensive (0.675)

Antineoplastic (0.910)

Antiseborrheic (0.891)

Alopecia treatment $(0.877)$

Gynecological disorders treatment (0.866)

Psychosexual dysfunction treatment $(0.821)$

Radiosensitizer (0.767)

Dermatologic (0.757)

Chemosensitizer (0.743)

Antipsoriatic (0.724)

Prostatic (benign) hyperplasia treatment $(0.713)$

Ovulation inhibitor (0.674)

Antineoplastic (0.883)

Antiseborrheic (0.877)

Gynecological disorders treatment (0.849)

Psychosexual dysfunction treatment (0.817)

Radiosensitizer (0.758)

Chemosensitizer (0.733)

Dermatologic (0.730)

Prostatic (benign) hyperplasia treatment (0.695)

Antipsoriatic (0.691)

Ovulation inhibitor (0.667)

Antineoplastic (0.844)

Psychosexual dysfunction treatment (0.756)

Radiosensitizer (0.738)

Antiosteoporotic (0.730)

Bone diseases treatment (0.726)

Gynecological disorders treatment (0.693)

Chemosensitizer (0.684)

Dermatologic (0.653)

Prostatic (benign) hyperplasia treatment $(0.631)$

Antipsoriatic (0.634)0.870

Antineoplastic $(0.870)$

Psychosexual dysfunction treatment (0.772)

Radiosensitizer (0.740)

Gynecological disorders treatment (0.714)

Chemosensitizer (0.689)

Dermatologic (0.659)

Prostatic (benign) hyperplasia treatment $(0.647)$

Antipsoriatic (0.634)

Apoptosis agonist (0.597)

Antineoplastic (0.866)

Psychosexual dysfunction treatment (0.754)

Radiosensitizer (0.732)

Chemosensitizer (0.669)

Gynecological disorders treatment (0.631)

Antimetastatic (0.614)

Antipsoriatic (0.603)

Dermatologic (0.547)

Antineoplastic (0.876)

Apoptosis agonist (0.807)

Radiosensitizer (0.718)

Dermatologic (0.717)

Severe acute respiratory syndrome treatment $(0.690)$

Antipsoriatic (0.670)

Chemosensitizer (0.668)

Immunosuppressant (0.653)

Psychosexual dysfunction treatment (0.648)

Hepatic disorders treatment $(0.638)$

Antiinflammatory (0.594)

Antiviral (0.546) 


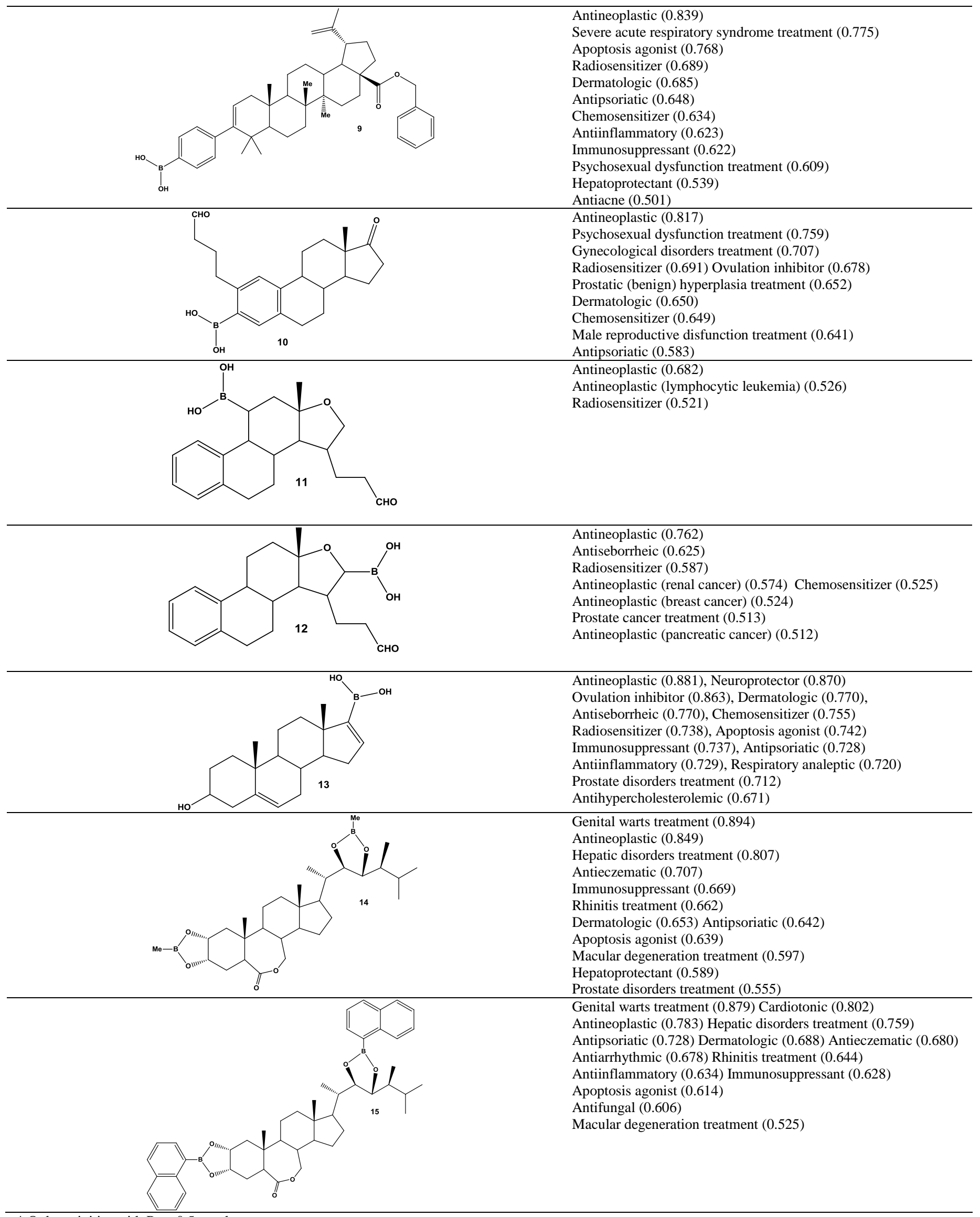




\section{ARSENOSTEROIDS}

Arsenic compounds, including hydrocarbons, lipids, phospholipids, fatty acids and sugars, are often found in nature (Dembitsky and Rezanka, 2003; Dembitsky and Levitsky, 2004). Arsenolipid analogues of phosphatidylcholine, sphingomyelin and fatty acids are found in fish, crustaceans, lichens, mollusks, sponges, and other species of marine and freshwater invertebrates as well as brown and green algae (Khan and Francesconi, 2016; Arroyo-Abad et al., 2016; Yu et al., 2018). Many studies have shown that arsenolipids are inhibitors of glycerin kinase, bovine carbonic anhydrase, promyelocytic leukaemia and inhibit the growth of certain types of cancer cells (Roggenbeck et al., 2016; Sele et al., 2012). Surprisingly, arsenosteroids are not found in nature.

Apparently, this is due to the problem of isolation and identification of these compounds. In the near future, these interesting and possibly biologically active compounds will be found in many species of marine organisms (Arroyo-Abad et al., 2016; Yu et al., 2018; Dembitsky and Levitsky, 2004). Synthetic arsenosteroids form a small group of compounds and their activity is shownin Table 2. Arsenosteroids have shown anticancer activity (Table 2).

Table 2: Predicted biological activities of arsenosteroids (16-22).

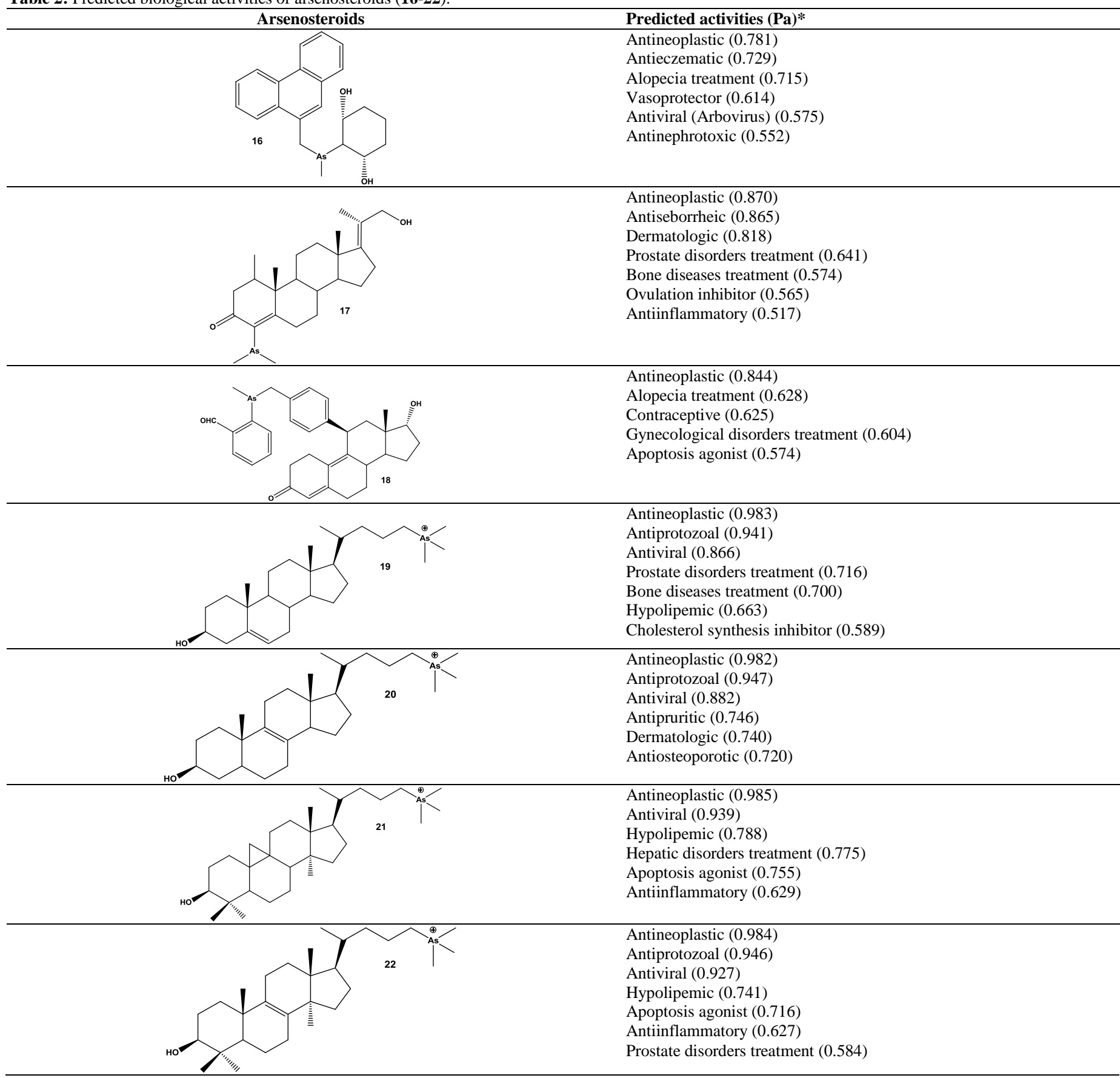

\footnotetext{
* Only activities with $\mathrm{Pa}>0.5$ are shown.
} 


\section{ASTATOSTEROIDS}

Astatine (At) is natural radioelement that has short-lived isotopes, and synthetic organic astatine compounds are commonly used for radiotherapy (Kugler et al., 1985). Steroids containing astatine, which are called astatosteroids, were first synthesized approximately 40 years ago (Visser et al., 1981). Some astatosteroids (2- and 4-astatoestradiol and 6-At-cholesterol, 23, 24, 26 and 27) have been synthesized in high radiochemical yields by the reaction of ${ }^{211} \mathrm{At} / \mathrm{I}_{2}$ and the corresponding chloromercury compounds. The stability in vitro was determined under different conditions in comparison with the analogous iodo compounds (Kugler et al., 1985). More recently, 6-astatomethyl-19norcholest-5(10)-en-3 $\beta$-ol (26) was synthesized at a yield of 60 $70 \%$ (Liu et al., 1985). The biological activity of these compounds has not been determined. The predicted biological activity of astatosteroids is presented in Table 3. The most characteristic biological properties for these steroids were antineoplastic, antiseborrheic, anti-secretoric and anti-hypercholesterolemic activities.

Table 3: Predicted biological activities of astatosteroids (23-27).

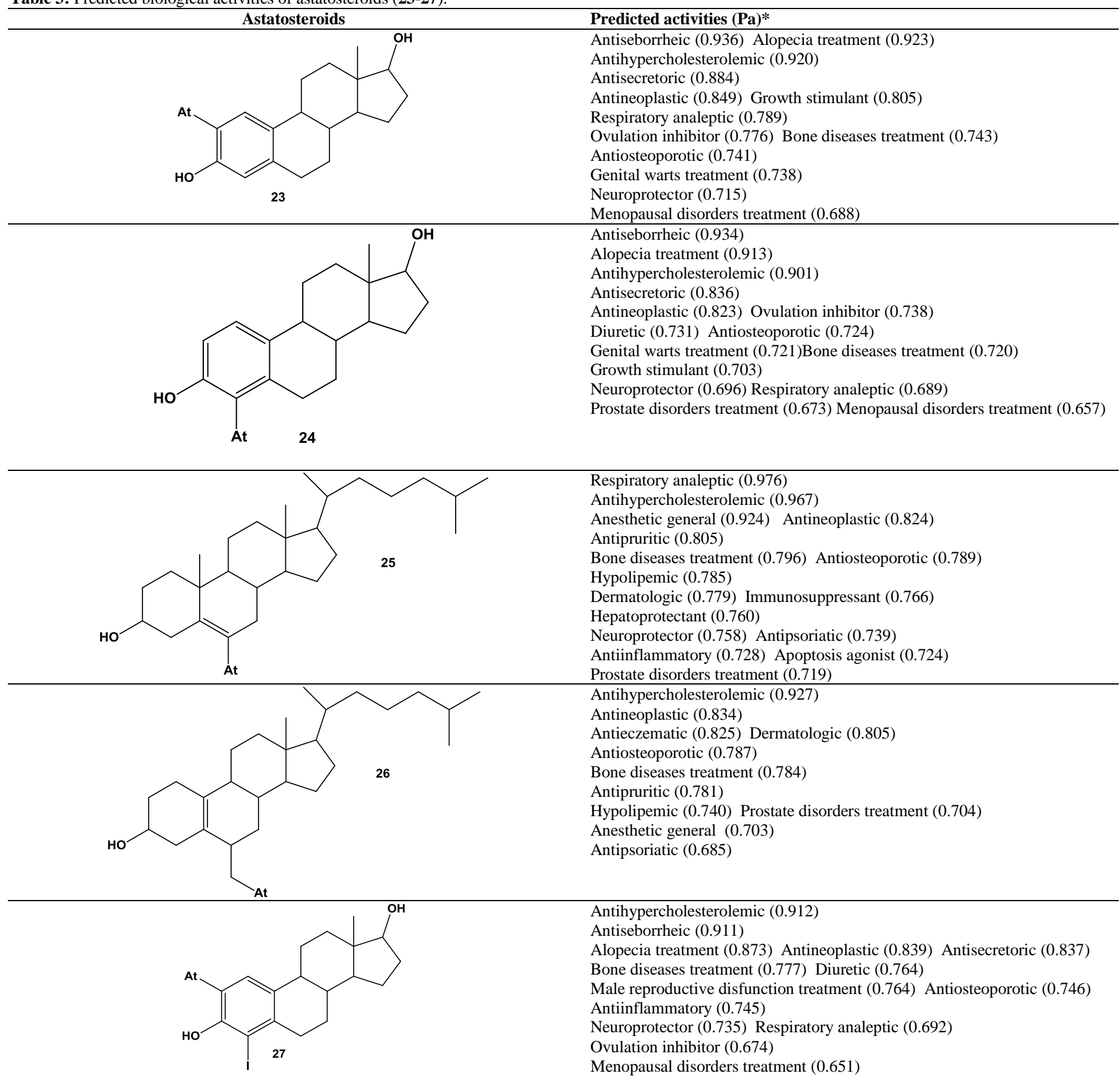

\footnotetext{
* Only activities with $\mathrm{Pa}>0.5$ are shown.
} 


\section{GERMYLATED STEROIDS}

In 2016, one hundred and thirty years have passed since the discovery of the element Germanium (Ge), and the synthesis of its first organic compounds. However, this area of element-organic chemistry began to develop most intensively only in the 1950 s (Rappoport, 2003; Terent'ev et al., 2011). In those years,the chemistry of organogermanium compounds was so poorly studied that it was not even possible to determine the biological activity and mechanisms of action on a living organism. Organogermanium compounds show anti-tumour, antiviral, immunomodulating, neurotropic, cardiovascular, and radioprotective activities. According to the literature, organogermanium compounds have a wide spectrum of biological activity but unlike silicon compounds they are practically nontoxic (Menchikov and Ignatenko, 2013; Lukevics et al.,1990; Asai, 1977). Several germylated steroids in position 16 were synthesized by the addition of trichlorogermane to a conjugated $\Delta 16$-double bond. The 16 $\alpha$-trichlorogermyl-3 $\beta$-acetoxy-pregnan-20-ones (28 and 29) and 16 $\alpha$-trimethylgermyl-progesterones (30-35) showed that it is very stable (Karpenko et al., 1998, 1999, 2011). An unusual germylated steroid (36) has been obtained from a $\Delta 16$ allopregnene-20 one (Heusler et al., 1959). The biological activity of these compounds has not been reported, and the predicted biological activity of germylated steroids is presented in Table 4. The most characteristic biological properties for these steroids were antineoplastic, anti-seborrheic and dermatologic activities.

Table 4: Predicted biological activities of germylated steroids (28-36). Germylated steroids Additional predicted activities (Pa)*

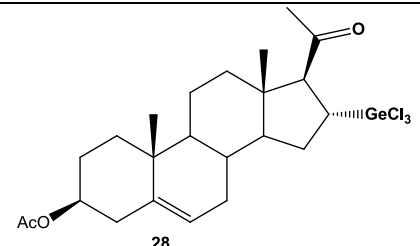

Respiratory analeptic $(0.870)$ Antineoplastic (0.860)

Antihypercholesterolemic (0.806)

Neuroprotector $(0.798)$

Antiseborrheic (0.782)

Ovulation inhibitor $(0.775)$

Anesthetic (0.738)

Menopausal disorders treatment (0.732)

Prostate disorders treatment $(0.721)$

Antipruritic (0.718)

Antiinflammatory (0.698)

Dermatologic (0.688)

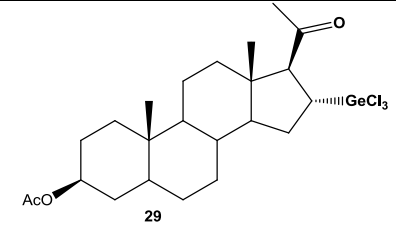

Respiratory analeptic $(0.874)$

Antiseborrheic (0.868) Anesthetic

general (0.856) Antineoplastic

(0.852)

Erythropoiesis stimulant (0.827)

Antipruritic (0.737)

Neuroprotector $(0.726)$

Cytoprotectant $(0.714)$

Antieczematic (0.712)

Prostate disorders treatment $(0.702)$

Menopausal disorders treatment (0.674)

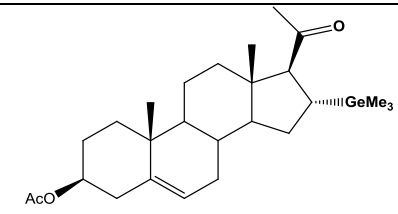

Antineoplastic (0.957)

Antiacne (0.939) Dermatologic

(0.928)

Respiratory analeptic $(0.779)$

Neuroprotector $(0.734)$

Ovulation inhibitor (0.724)

Prostate disorders treatment $(0.704)$

Antihypercholesterolemic (0.700)
Menopausal disorders treatment (0.679)

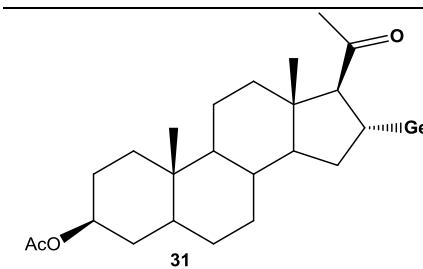

Antineoplastic (0.961)

Antiacne (0.952)

Dermatologic (0.935)

Antiseborrheic (0.830)

Erythropoiesis stimulant (0.793)

Respiratory analeptic (0.785)

Anesthetic general (0.735) Prostate

disorders treatment $(0.681)$

Antipruritic (0.679) Antieczematic (0.675)

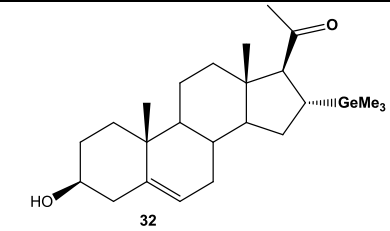

Antineoplastic (0.960) Antiacne

(0.951)

Dermatologic (0.940) Anesthetic

general $(0.841)$

Ovulation inhibitor $(0.774)$

Erythropoiesis stimulant (0.770)

Menopausal disorders treatment

(0.741)

Antihypercholesterolemic (0.738)

Neuroprotector (0.729)

Prostate disorders treatment $(0.720)$

Respiratory analeptic (0.715)

Antieczematic (0.695)

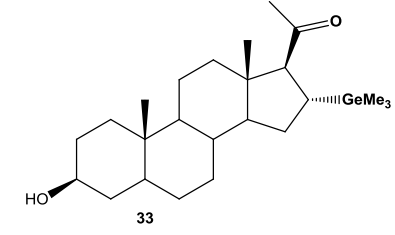

Antineoplastic (0.964) Antiacne

(0.960) Dermatologic (0.948)

Anesthetic general (0.915)

Erythropoiesis stimulant (0.896)

Antiseborrheic (0.797)

Antieczematic (0.735)

Respiratory analeptic (0.722)

Prostate disorders treatment $(0.700)$

Menopausal disorders treatment (0.682) Antipruritic (0.681)

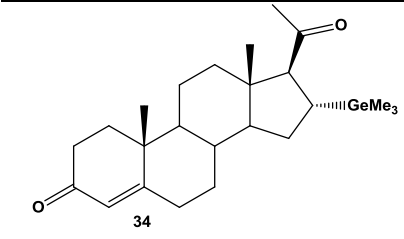

Antiacne (0.970) Antineoplastic

(0.969) Dermatologic (0.955)

Anesthetic general (0.816)

Ovulation inhibitor (0.745) Prostate

disorders treatment $(0.738)$

Antiseborrheic (0.691) Antipruritic

(0.673) , Menopausal disorders

treatment (0.665) Erythropoiesis stimulant (0.655) Prostatic (benign) hyperplasia treatment $(0.649)$

Antiacne (0.980)

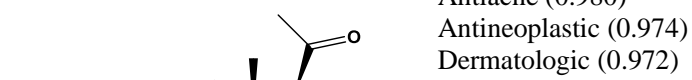

Antiseborrheic (0.831)

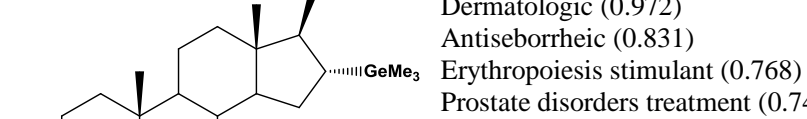

Prostatic (benign) hyperplasia

treatment $(0.651)$

Anesthetic general (0.631)

Menopausal disorders treatment (0.606)

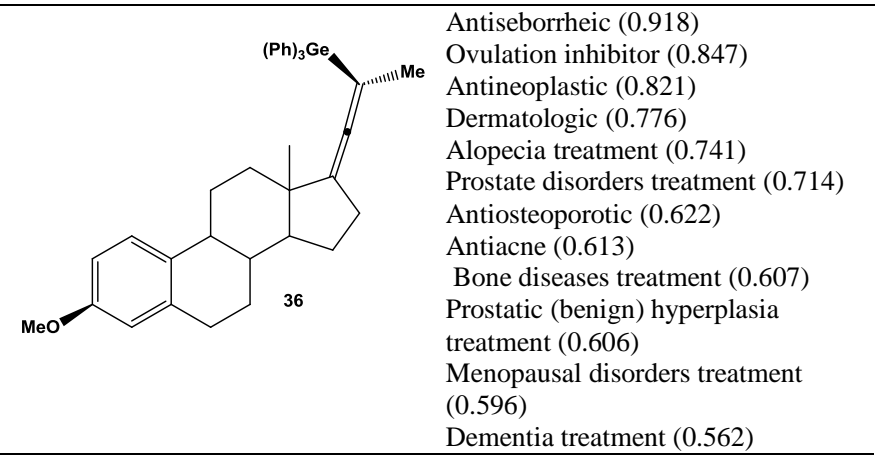

* Only activities with $\mathrm{Pa}>0.5$ are shown. 


\section{SILASTEROIDS}

The element silicon (Si) and organosilicon compounds belong to a class of metalloids. Silicon derivatives, such as sugars and other organic compounds, are widely used in the pharmaceutical industry and medicine (Lee, 2017; Terent'ev et al., 2011). Silicon-containing steroids, which are usually called silasteroids, are synthesized as potential oestrogenic agents, antiestrogenic, and antifertility agents (Lukevics et al., 1990; Garson and Kirchner, 1971; Simon, 2014). Silasteroids (37-42) containing the silicone atom in position 6 constitute the bulk of the known synthetic steroids (McPhail and Miller, 1975; Pitt et al., 1975). The main properties that are characteristic of these compounds are antineoplastic, psychotropic and anti-seborrheic activities (Table $5)$.

Steroids of 10- (44) and 13-silasteroids (45) containing silicone at position 10 and 13 were synthesized (Ouhabi, 2006; Díez-González et al., 2008; Blanco et al., 2005) but their activity was not studied. Both of these compounds show antineoplastic activity and have a Pa greater than 0.97 . The biological activities of other silasteroids are shown in Table 5.

Table 5: Confirmed and predicted biological activities of silasteroids (37-48).

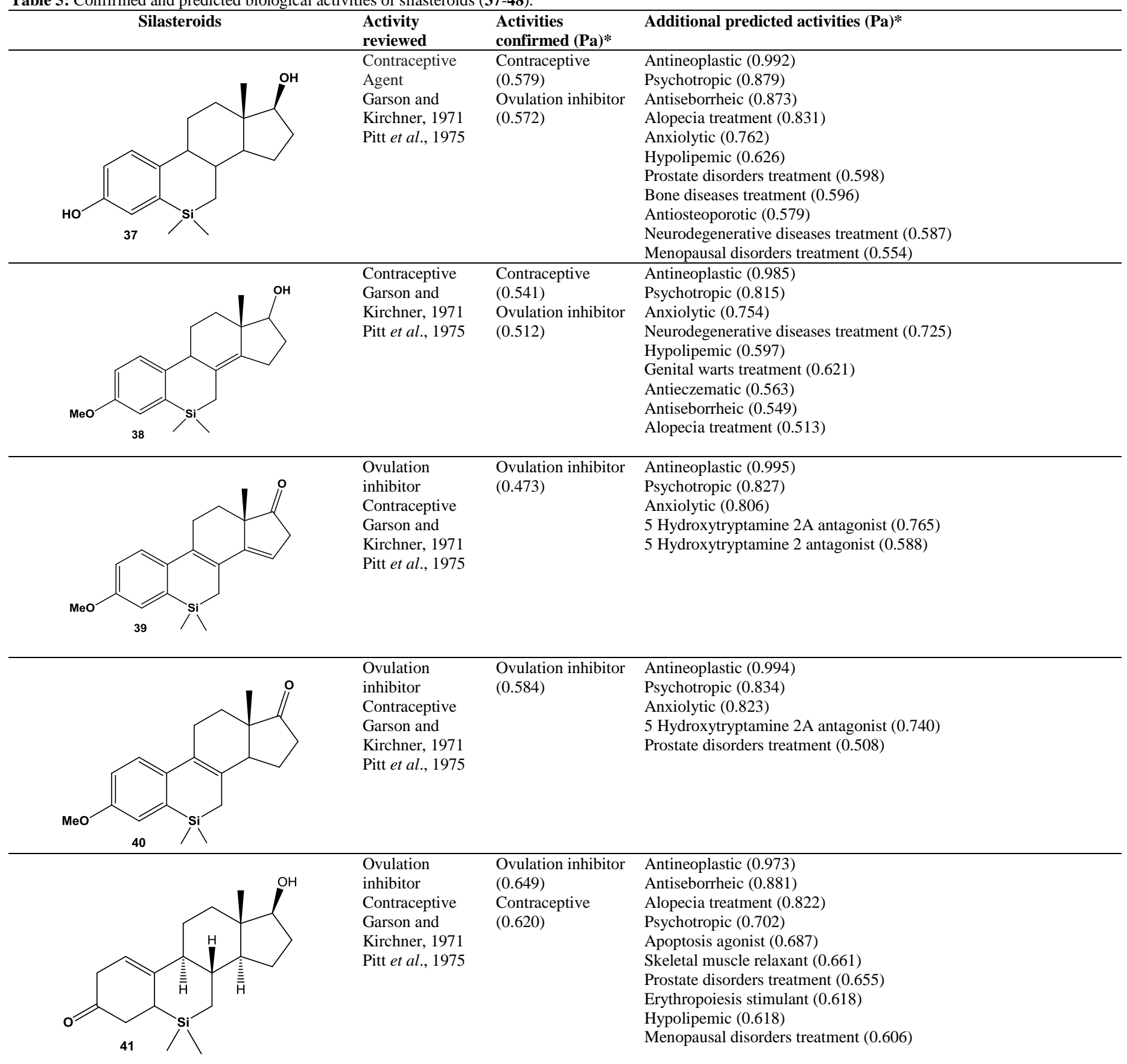




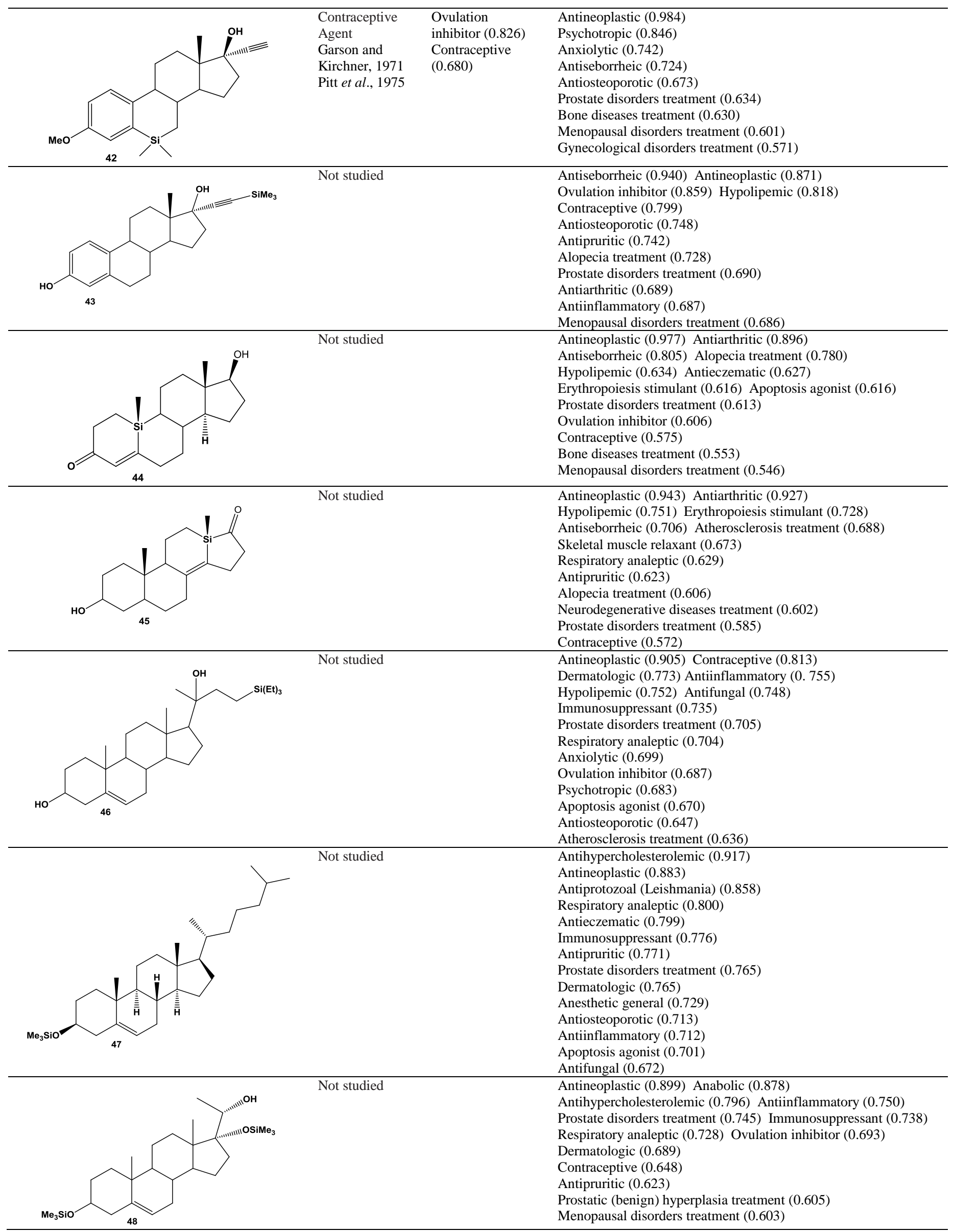




\section{SELENA STEROIDS}

Selenium (Se) is a chemical element belonging to the 16th group of the periodic table and was discovered by Jöns Jacob Berzelius, a Swedish chemist, in 1817 (Rheinboldt, 1955). Selenium is an essential metalloid and it is one of the most necessary trace elements for humans (Conor, 2006). Selenium occupies an important place in the regulation of metabolism in humans and therefore it is necessary to monitor its presence in consumed foods (Terry et al., 2000). The Allium and Brassica families as well as Brazil nuts, mushrooms (shiitake and white mushrooms), beans, chia seeds, brown rice, sunflower, sesame and flax seeds, and cabbage and spinach contain high enough selenium and organoselenium concentrations (Pilon-Smits, 2015). Organoselenium compounds are chemical compounds containing bonds between carbon atoms and selenium (C-Se). These compounds are widely used in organic synthesis including the synthesis of pharmaceuticals. Organoselenium chemistry examines the properties and reactivity of selenium compounds. Recently, a large number of original books on the chemistry, biology, and medicine of organoselenium compounds have been published (Santi, 2014; Back, 1999). There are also many excellent reviews in the literature, which are devoted to the biological role and functions of organoselenium compounds ( $\mathrm{Li}$ et al., 2013). Apparently, selena steroids are the main group of the essential metalloids that have been synthesized over the past 50 years and approximately 300 have been synthesized (Wirth, 2011; IbrahimOuali et al., 2011; Ibrahim-Ouali, 2009). The selena steroids selected for this study are presented in Table 6 . They can be contingently divided into four groups. The first group includes steroids in which the selenium atom is incorporated into the heterocycle of the core molecules $(49,50,51$ and 52). For the selena steroids of this group, the main characteristics are antineoplastic and anti-seborrheic activities. Additionally, these Selena steroids of this group can be used to treat Alzheimer's disease (Table 6). The second group includes steroids where selenium is in the second and third positions of the steroid (53-58). For selena steroids of the second group, the main activities are antineoplastic, anti-hypercholesterolemia and anti-inflammatory. The third group includes steroids in which the selenium atom is in position six of the core molecules $(\mathbf{5 9 - 6 8 , 7 0})$. For selena steroids of the third group $(\mathbf{6 9}, \mathbf{7 1 - 7 6})$, respiratory analeptic, anaesthetic and anti-hypercholesterolemic are the main activities. In addition, they can be used as chemopreventive and hepatoprotectant agents. The fourth group includes steroids in which the selenium atom is in the hydrocarbon tail of the steroid (77-84). For the fifth group (85-88), the main activities are antiarthritic and antineoplastic. In addition, they can be used as for hypolipemic, anti-atherosclerosis, lipoprotein disorders and as antioxidant agents.

Table 6: Predicted biological activities of selena steroids (49-85).

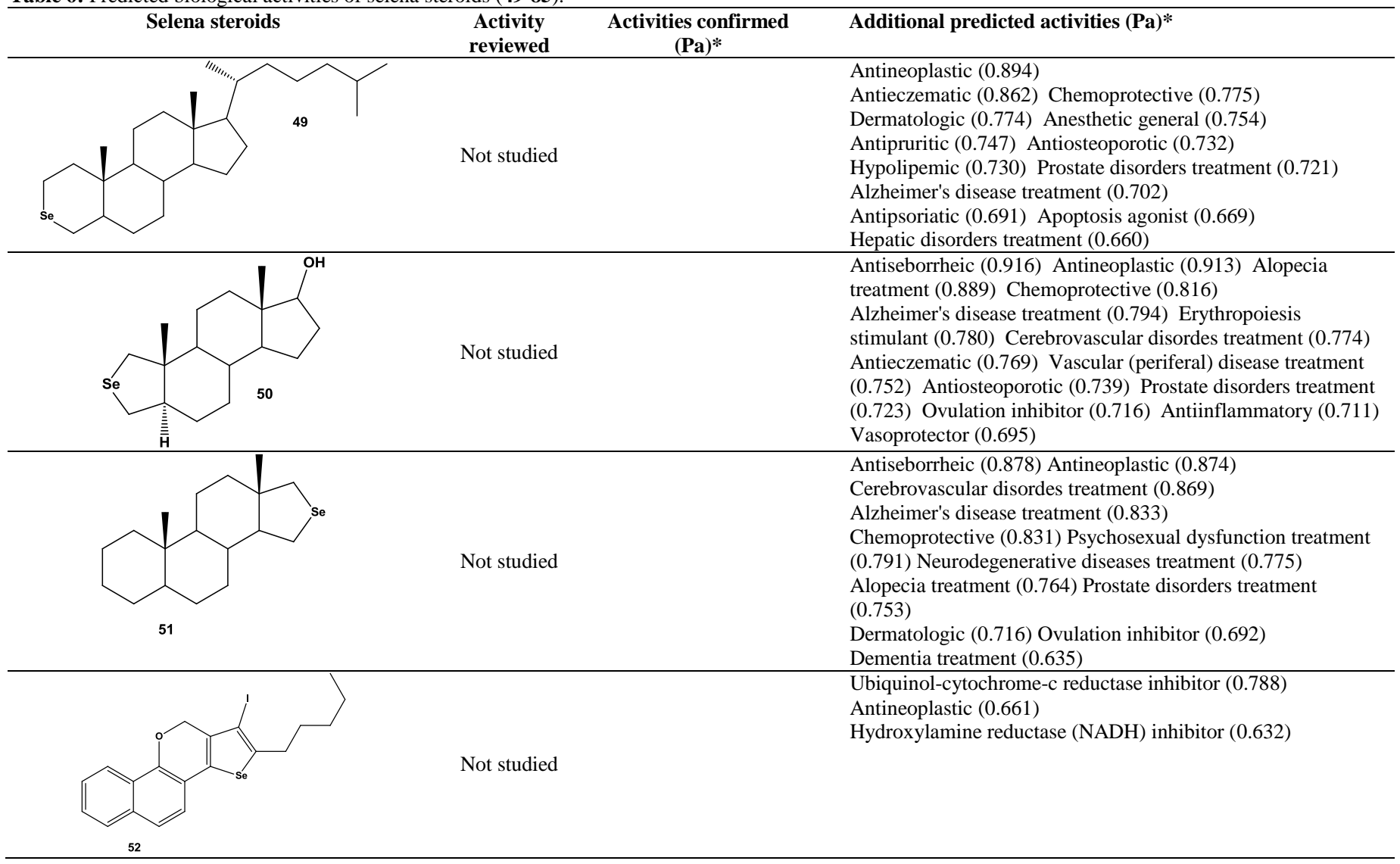




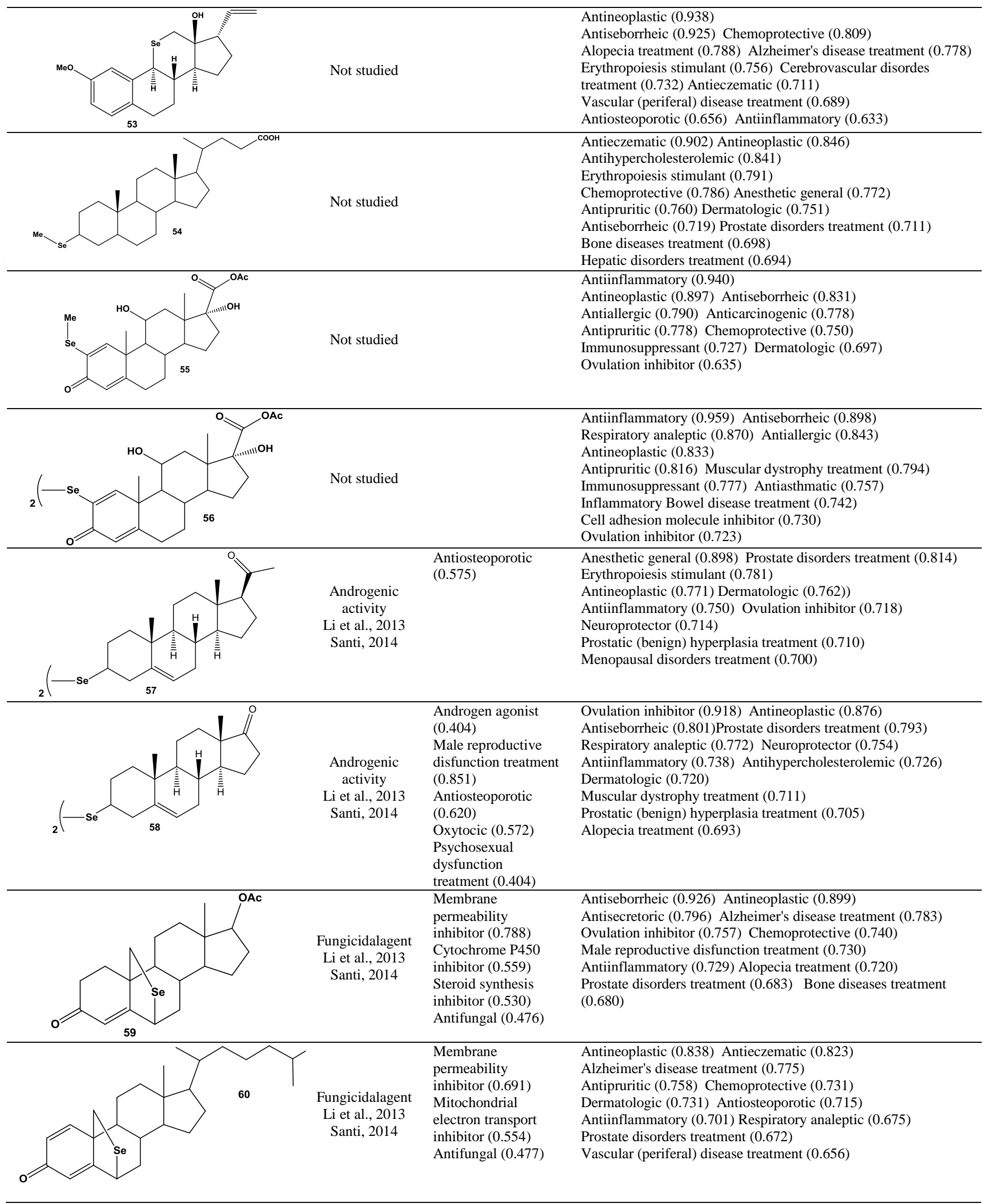




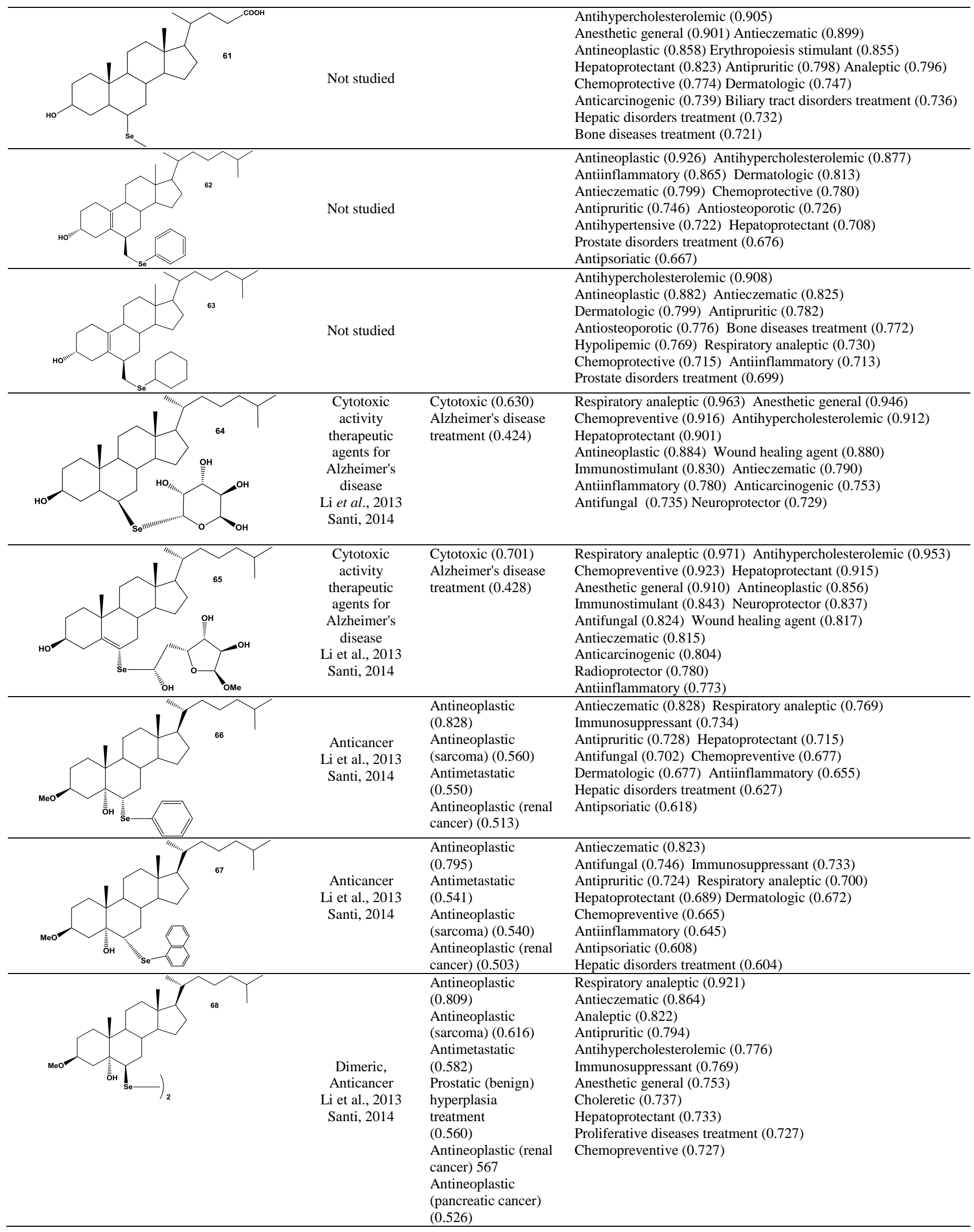




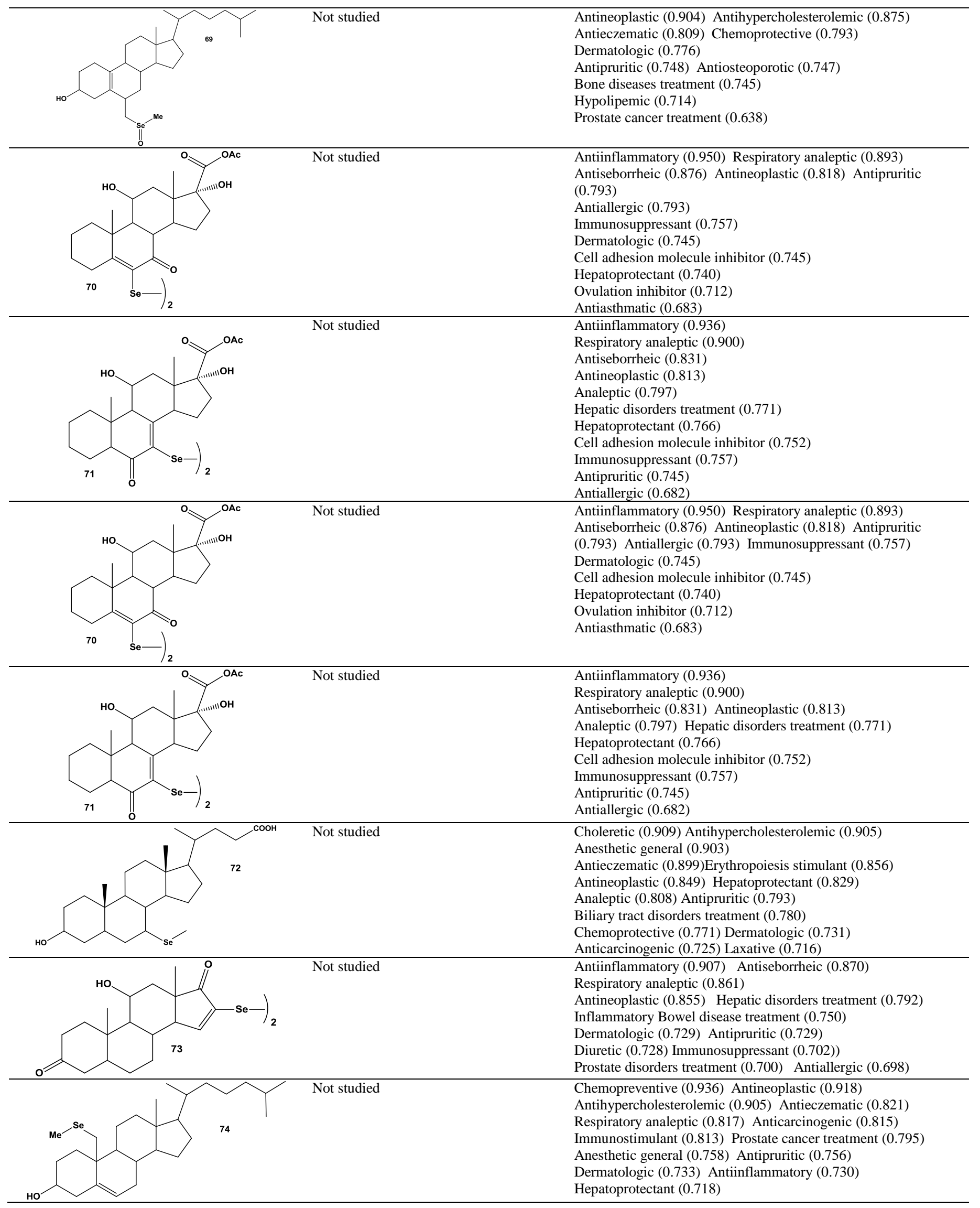




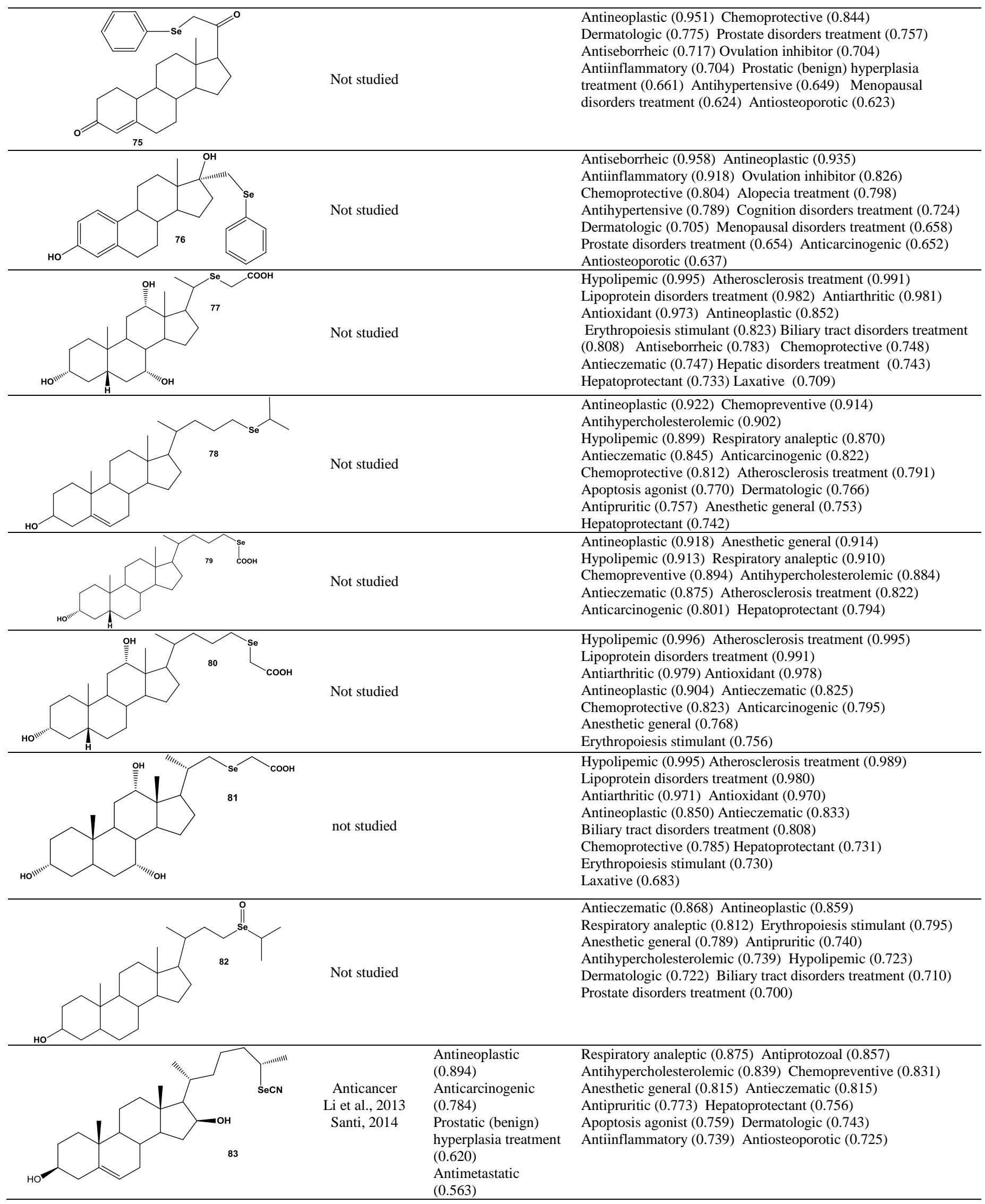




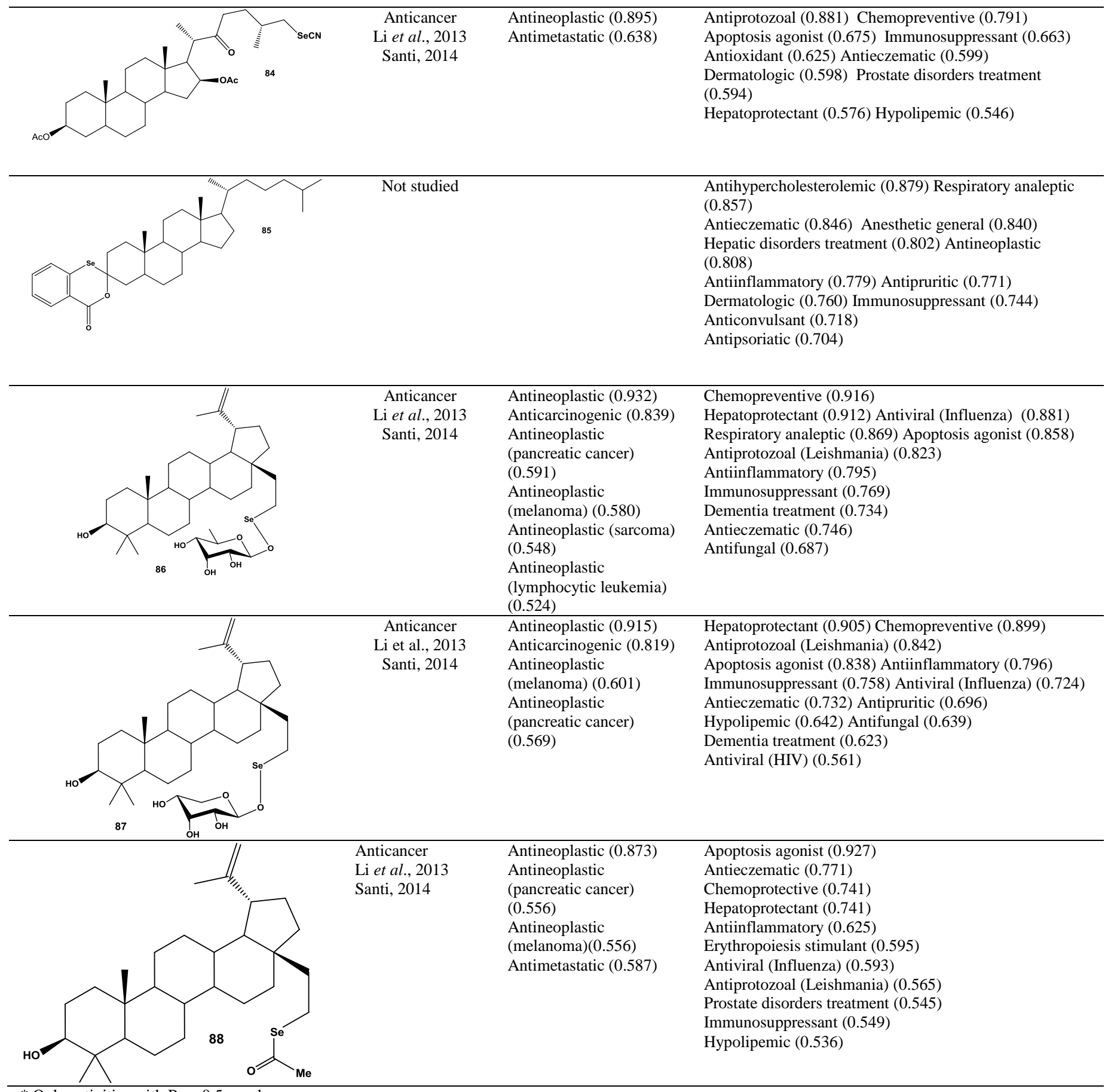

* Onlv activities with $\mathrm{Pa}>0.5$ are shown

\section{TELLURA STEROIDS}

Tellurium (Te) is a toxic metalloid that was discovered by Franz-Joseph Müller von Reichenstein in 1782 (Divers and Shimosé, 1883). Organotellurium chemistry addresses the synthesis and properties of chemical compounds containing a carbon bond with tellurium. A large number of publications have been devoted to this topic but it is not a topic for our research (Sadekov et al., 1987). Tellura steroids are a rare group of organic synthetic compounds whose biological activity is of great interest for medicine, pharmacology, and the pharmaceutical industry
(Ibrahim-Ouali, 2010, 2015; Knapp, 1980). For tellura steroids (89-93,96), whose tellurium is incorporated into the steroid skeleton, the following basic properties are characteristics: antioxidant, anti-inflammatory, antineoplastic, antiseborrheic, and antiprotozoal activities, and they can be used as anti-parkinsonian, anti-Alzheimer's disease and anti-neurodegenerative agents (Table 7). For tellura steroids (97 and 98), anti-inflammatory, antioxidant and anticancer properties are characteristics. The biological activities of other tellura steroids $(\mathbf{9 4}, \mathbf{9 5}, \mathbf{9 9 - 1 0 2})$ are presented in Table 7. 
Table 7: Predicted biological activities of tellura steroids (89-105).

Activity reviewed $\begin{gathered}\begin{array}{c}\text { Activities confirmed } \\ (\mathbf{P a})^{*}\end{array} \\ \text { Not studied }\end{gathered}$

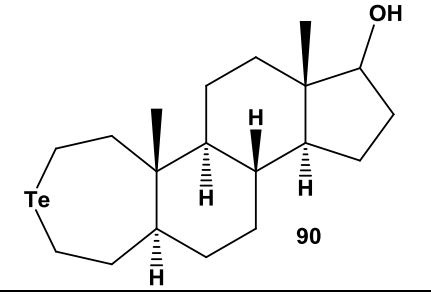<smiles>C=C[C@H]1CCC2C3CCc4ccc(OC)cc4C3[Te]C[C@]21O</smiles>

91
Not studied

Not studied

Not studied

Not studied
Antioxidant (0.946) Antiseborrheic (0.933)

Antiinflammatory (0.930) Antineoplastic (0.930)

Alopecia treatment (0.889) Anesthetic general (0.879)

Neurodegenerative diseases treatment $(0.871)$

Alzheimer's disease treatment (0.863)

Atherosclerosis treatment (0.861) Respiratory analeptic

(0.850) Erythropoiesis stimulant (0.846)

Antiparkinsonian (0.833) Antiosteoporotic (0.783)

Antihypercholesterolemic (0.769)<smiles>C=C[C@H]1CCC2C3CCc4cnccc4C3[Te]C[C@@]21O</smiles>

92<smiles>CC[C@H](C)C(C)[C@@H](C)CCCC(C)C</smiles>

93<smiles>CC1C(C2CCCC2)CCC2C[Te]CC[C@@]21C</smiles>

Antiprotozoal (Plasmodium) (0.818)

Antiprotozoal (0.801)

Antiinflammatory (0.779)

Antioxidant (0.774)

Alzheimer's disease treatment (0.757)

Neurodegenerative diseases treatment (0.735)

Antiparkinsonian (0.730)

Antineoplastic (0.725)

Atherosclerosis treatment (0.670)

Ovulation inhibitor $(0.625)$

Neurodegenerative diseases treatment $(0.825)$

Antiprotozoal (Plasmodium) (0.823)

Antiparkinsonian (0.817)

Antiprotozoal (0.810)

Alzheimer's disease treatment (0.799)

Antiinflammatory (0.789)

Antineoplastic (0.759)

Antioxidant (0.736)

Atherosclerosis treatment (0.649)

Antiinflammatory (0.908)

Anesthetic general (0.898)

Atherosclerosis treatment (0.896)

Antieczematic (0.887)

Antineoplastic (0.872)

Respiratory analeptic (0.872)

Antihypercholesterolemic (0.864)

Antioxidant (0.849)

Alzheimer's disease treatment $(0.843)$

Neurodegenerative diseases treatment (0.819)

Antiosteoporotic (0.802)

Prostate disorders treatment $(0.754)$

Antiparkinsonian (0.744)<smiles>CC1C2CC=C3C[C@H](Cc4ccccc4)CC[C@]3(C)C2CCC1(C)C</smiles>

\section{Antineoplastic}

(0.828)

Prostatic (benign)

hyperplasia treatment

(0.678)

Anticancer

Knapp, 1980
Antineoplastic

(pancreatic cancer)

(0.522)

Prostate cancer

treatment $(0.501)$
Antiarthritic (0.969)

Antioxidant (0.967)

Antihypercholesterolemic (0.889)

Anesthetic general (0.845)

Antieczematic (0.828)

Respiratory analeptic (0.826)

Antiinflammatory (0.794)

Antipruritic (0.780)

Dermatologic (0.772)

Prostate disorders treatment $(0.744)$

Antiosteoporotic (0.717)

Atherosclerosis treatment (0.703)

Alzheimer's disease 0.966 treatment (0.526) 


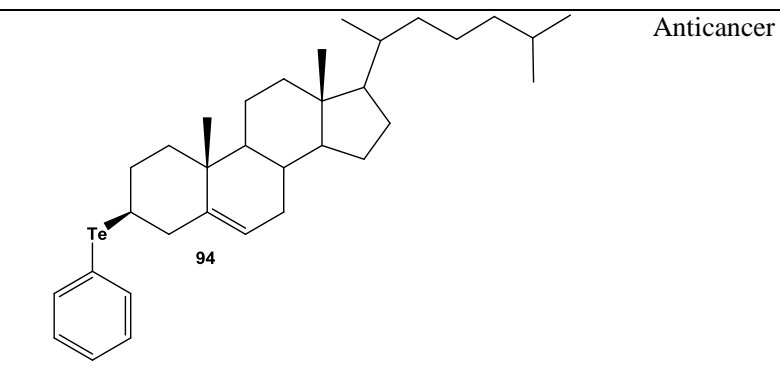

Antineoplastic
$(0.828)$
Prostatic (benign)
hyperplasia treatment
$(0.678)$
Antineoplastic
(pancreatic cancer)
$(0.522)$
Prostate cancer
treatment $(0.501)$

\author{
Antiarthritic (0.969) \\ Antioxidant (0.967) \\ Antihypercholesterolemic (0.889) \\ Anesthetic general $(0.845)$ \\ Antieczematic (0.828) \\ Respiratory analeptic $(0.826)$ \\ Antiinflammatory (0.794) \\ Antipruritic (0.780) \\ Dermatologic (0.772) \\ Antiosteoporotic (0.717)
}

treatment $(0.501) \quad$ Prostate disorders treatment $(0.744)$

Atherosclerosis treatment (0.703)

Alzheimer's disease 0.966 treatment $(0.526)$

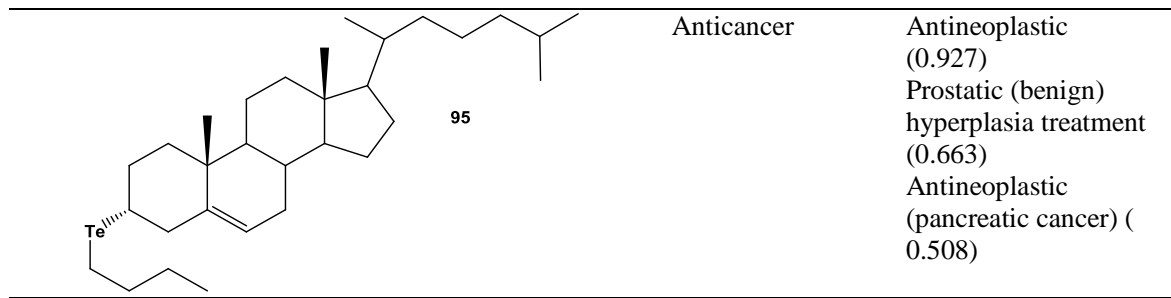

Antioxidant (0.966) Atherosclerosis treatment (0.964)

Antiinflammatory (0.955) Antiparkinsonian (0.946)

Neurodegenerative diseases treatment $(0.945)$

Alzheimer's disease treatment (0.928)

Antihypercholesterolemic (0.886) Anesthetic general

(0.845) Antieczematic (0.836)

Respiratory analeptic (0.791) Antipruritic (0.781)

Dermatologic (0.760) Prostate disorders treatment (0.730) Antiosteoporotic (0.683)

Not studied

Antiinflammatory (0.908) Anesthetic general (0.898)

Atherosclerosis treatment (0.896)

Antieczematic (0.887) Antineoplastic (0.872)

Respiratory analeptic (0.872) Antihypercholesterolemic (0.864) Antioxidant (0.849)

Alzheimer's disease treatment (0.843)

Antiosteoporotic (0.802) Antipruritic (0.792)

Prostate disorders treatment $(0.754)$

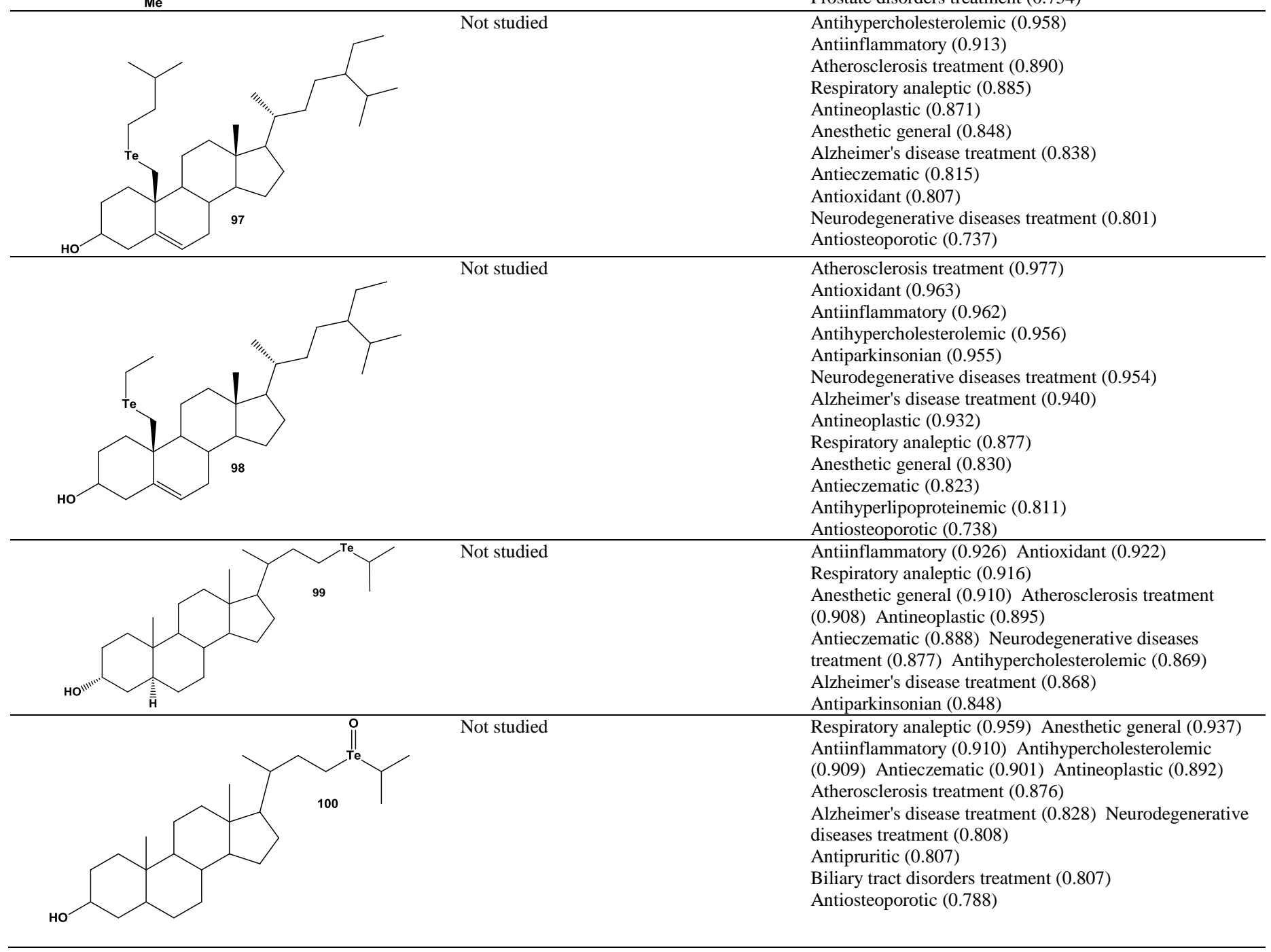




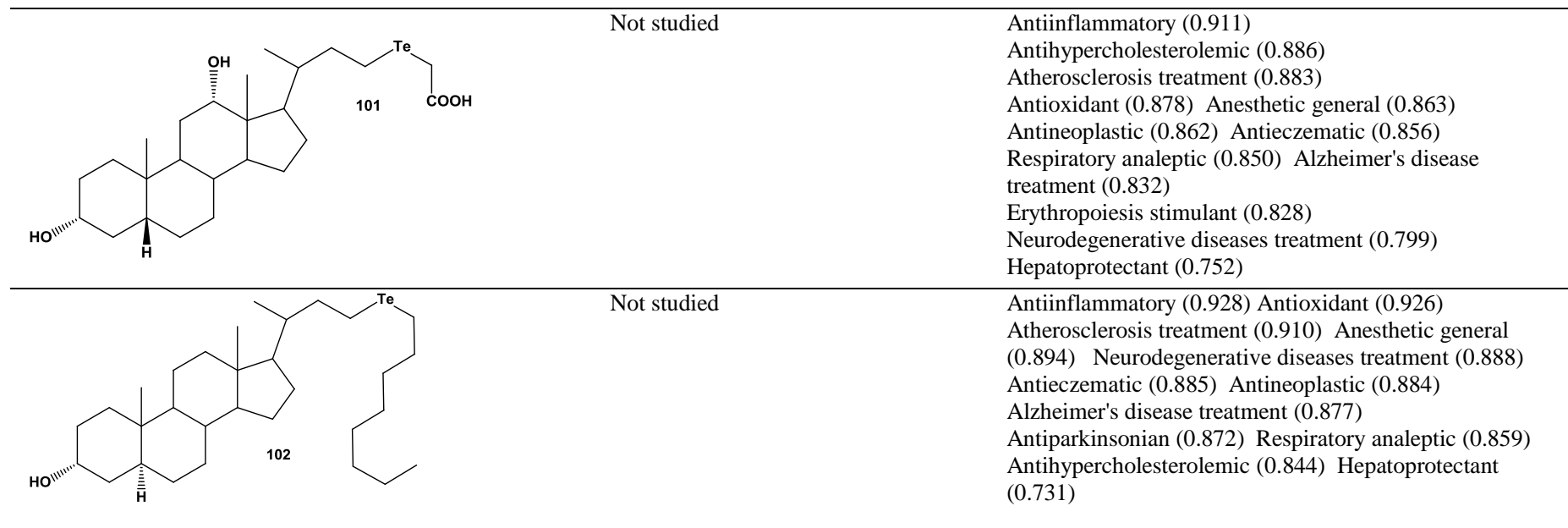

* Only activities with $\mathrm{Pa}>0.5$ are shown

\section{CONCLUSION}

In this review, we present the structures of OS that contain (with the composition of a molecule of metals or metalloids) As, At, B, Ge, Si, Se, and Te that belong to seven groups that include boronic steroids, arsenosteroids, astatosteroids, germylated steroids, silasteroids, selena steroids and tellura steroids. The biological activity for these groups of steroids is presented in this paper. The most characteristic biological activities for astatosteroid steroids were antineoplastic, antiseborrheic, anti-hypercholesterolemic, anti-secretoric and antihypercholesterolemic activities. The most characteristic biological activities for germylated steroids were antineoplastic, antiseborrheic and dermatologic activities. The main activities that are characteristic of silasteroids are antineoplastic, psychotropic and anti-seborrheic activities. Additionally, these selena and tellura steroids showed a high anticancer activity, and they can be used as anti-parkinsonian, anti-Alzheimer's disease and antineurodegenerative agents.

\section{ACKNOWLEDGEMENT}

Financial support and sponsorship: The work was supported in the framework of the Russian state Academies of Sciences Fundamental Research Program for 2013-2020 (Moscow \& Vladivostok).

Conflict of Interests: There are no conflicts of interest.

\section{REFERENCES}

Ali HA, Dembitsky VM, Srebnik M. 2005.Contemporary Aspects of Boron: Chemistry and Biological Applications. Elsevier, Amsterdam.

Arroyo-Abad U, Pfeifer M, Mothes S, Stärk H-J, Reemtsma T. Determination of moderately polar arsenolipids and mercury speciation in freshwater fish of the River Elbe (Saxony, Germany). Environ Pollut, 2016; 208: 458-466.
Asai K. 1977. Organic Germanium: A Medical Godsend, Kogakusha Ltd., Tokyo.

Back TG. 1999. Organoselenium Chemistry: A Practical Approach. 1st Ed., Oxford University Press.

Blanco L, Diez-Gonzalez S, Ouabi K. 2005.On the way to 10 and 13-silasteroids, 14th International Symposium on Organosilicon Chemistry, Würzburg, Germany,July 31- August 5.

Borodina Yu, Sadym A, Filimonov D, Blinova V, Dmitriev A, Poroikov V. Predicting biotransformation potential from molecular structure. J Chem Inform Comput Sci, 2003; 43: 1636-1646.

Charney W, Herzog HL. 1967. Microbial Transformations of Steroids: A Handbook. Academic Press.

Chiusoli GP, Salerno G, Bergamaschi E, Andreetti GD, Bocelli G, Sgarabotto P. Total synthesis of steroid analogues by organometallic procedures. J Organomet Chem, 1979; 177: 245-253. MA, USA

Conor R. 2006. Selenium in Food and Health.Springer, Boston,

Coogan MP, Dyson PJ, Bochmann M. Introduction to the organometallics in biology and medicine issue. Organometallics, 2012; 31: $5671-5672$.

Dembitsky VM, Ali HA, Srebnik M. Recent chemistry of diboron compounds. Adv Organomet Chem, 2004; 193-250.

Dembitsky VM, Ali HA, Srebnik M. Recent development in bisdiborane chemistry: B-C-B, B-C-C-B, B-C $=\mathrm{C}-\mathrm{B}$, and B-C $\equiv \mathrm{C}-\mathrm{B}$. Appl Organometal Chem, 2003; 17: 327-345.

Dembitsky VM, Gloriozova TA, Poroikov VV. Pharmacological activities of epithio steroids.J Pharm Res Int. 2017; 18(4): 1-19. DOI: 10.9734/JPRI/2017/36199.

Dembitsky VM, Levitsky DO. Arsenolipids. Prog Lipid Res, 2004; 43:403-448.

Dembitsky VM, Quntar A, Srebnik M. Natural and synthetic small boron-containing molecules as potential inhibitors of bacterial and fungal quorum sensing. Chem Rev, 2011; 111: 209-237.

Díez-González S, Paugam R, Blanco L. Synthesis of 1Silabicyclo(4.4.0)dec-5-en-4-ones: A Model of the A and B Rings of 10Silatestosterone. Eur J Org Chem, 2008; 3298-33073.

Divers E, Shimosé M.On a new oxide of tellurium. J Chem Soc, 1883; 43: 319-323.

Filz OA, Poroikov VV. Design of chemical compounds with desired properties using fragment libraries. Russ Chem Rev, 2012; 81:158174.

Fiorucci S, Distrutti E, Bifulco G, D'Auria MV, Zampella A. Marine sponge steroids as nuclear receptor ligands. Trends Pharmacol Sci, 2012; 33: 591-601.

Fuentes-Aguilar A, Romero-Hernández LL, Arenas-González A, Merino-Montiel P, Montiel-Smith S, Meza-Reyes S, Vega-Báez JL, 
Plata GB, Padrón JM, López Ó, Fernández-Bolaños JG. New selenosteroids as antiproliferative agents. Org Biomol Chem, 2017; 15: 5041-5054.

Galán B, García-Fernández J, Felpeto-Santero C, FernándezCabezón L, García JL.2017. Bacterial metabolism of steroids. In: Aerobic Utilization of Hydrocarbons, Oils and Lipids. Springer International Publishing AG, 1-22.

Garson LR, Kirchner LK. Organosilicon entities as prophylactic and therapeutic agents. J Pharm Sci, 1971; 60: 1113-1127.

Guzman DC, Olguin HJ, Garcia EH, Soto MP, Garcia MS, Mejia GB. Natural steroids and androgen antagonists used as neuroprotectives in common neurological disorders. CNS Neurol Disord Drug Targets, 2017; doi: 10.2174/1871527316666170714121654.

Heusler K, Kebrle J, Meystre C, Ueberwasser H, Wieland P, Anner G, Wettstein A. Sterische Einflüsse einer 16 $\alpha$-Methylgruppe auf Reaktionen in der Seitenkette von Allopregnan-Verbindungen. Helv Chim Acta, 1959; 42: 2043-2062.

Ibrahim-Ouali M. Total synthesis of steroids and heterosteroids from BISTRO. Steroids, 2015; 98: 9-28.

Ibrahim-Ouali M. First total synthesis of 11-selena steroids. Tetrahedron Lett, 2009; 50:1607-1609.

Ibrahim-Ouali M. First total synthesis of 11-tellura steroids. Tetrahedron Lett, 2010; 51: 3610-3612.

Ibrahim-Ouali M, Romero E, Bouleghlem H.First total syntheses of ( \pm )-3-aza-11-selena and ( \pm )-3-aza-11-tellura steroids. Tetrahedron, 2011; 67: 3668-3676.

Jaouen G, Salmain M. 2015. Bioorganometallic Chemistry: Applications in Drug Discovery, Biocatalysis, and Imaging. John Wiley \& Sons, Inc, San Francisco.

Karpenko RG, Kolesnikov SP. Germylated steroids. 1. Hydrogermylation of conjugated steroid enones. Russ Chem Bull, 1998; 47: $180-182$

Karpenko RG, Kolesnikov SP. Germylated steroids. 2. Synthesis of steroid germatranes. Russ Chem Bull, 1999; 48: 1185-1186.

Karpenko G, Krylova IV, Kamernitskii AV. Germylated steroids.3. Synthesis of trialkylgermylated steroids. Russ Chem Bull, 2011; 60: 2100-2102.

Khan M, Francesconi KA. Preliminary studies on the stability of arsenolipids: Implications for sample handling and analysis. J Environ Sci, 2016; 49: 97-103.

Knapp FF. The synthesis of ${ }^{123}$ Te-labeled 17ß-hydroxy-2tellura-A-nor-5 $\alpha$-androstane. J Labelled Comp Radiopharm, 1980; 17: 8191. Heidelberg.

Kugler HK, Keller C. 1985.At Astatine.Springer-Verlag Berlin

Lagunin A, Zakharov A, Filimonov D, Poroikov V. QSAR modelling of rat acute toxicity on the basis of PASS prediction. Mol Informatics, 2011; 30: 241-250.

Lee VY. 2017. Organosilicon Compounds. Theory and Experiment (Synthesis). Academic Press, Cambridge, Massachusetts,USA.

Levitsky DO, Gloriozova TA, Poroikov VV, Dembitsky VM. Naturally occurring isocyano/isothiocyanato compounds: Their pharmacological and SAR activities. Mathews J Pharm Sci, 2016; 1(1): 003 .

Li QS, Wu DM, Zhu BC, Wang YG.Organic selenium resin in solid phase synthesis and its application in constructing medicinally relevant small organic molecules.Mini Rev Med Chem. 2013; 13:854-869.

Liu BL, Jin YT, Liu ZH, Luo C, Kojima M, Maeda M. Halogen exchanges using crown ethers: synthesis and preliminary biodistribution of 6-(211At)astatomethyl-19-norcholest-5(10)-en-3beta-ol. Int J Appl Radiat Isot, 1985; 36: 561-563.

Lukevits EYa, Gar TK, Ignatovich LM, Mironov VF. 1990. Biological Activity of Germanium Compounds. Riga, Zinatne, Latvia.
McPhail AT, Miller RW. Crystal structure and conformation of $17 \alpha$-ethynyl-17 $\beta$-hydroxy-6,6-di-methyl-6-sila-5 $\alpha$-estr-1(10)-en-3-one. J Chem Soc, Perkin Trans 2, 1975; 1180-1184.

Menchikov LG, Ignatenko MA. Biological activity of organogermanium compounds (A Review). Pharm Chem J, 2013; 46: 1-6.

Ouhabi K. 2006. Etudes de voies d'accès aux 13silastéroïdes.Thesis, Université de Paris-Sud. Paris, France.

Pilon-Smits EAH. Selenium in Plants. Prog Bot, 2015; 76: $93-$

106.

Pitt C, Friedman A, Rector D, Wani M. The total synthesis and anti-fertility activity of 6-silasteroids. Tetrahedron, 1975; 31: 2369-2377.

Rappoport Z. 2003. The Chemistry of Organic Germanium, Tin and Lead Compounds, Vol. 2, John Wiley \& Sons, Ltd. DOI: 10.1002/0470857188

Rheinboldt H. 1955. Selenium and Tellurium Chemistry, in Houben Weyl, Methoden der Organischen Chemie, vol. IX, Thieme Verlag: Stuttgart, Germany.

Roggenbeck BA, Banerjee M, Leslie EM. Cellular arsenic transport pathways in mammals. J Environ Sci, 2016; 49: 38-58.

Sadekov ID, Rivkin BB, Minkin VI. Organotellurium compounds in organic synthesis. Russ Chem Rev, 1987; 56: 4-51.

Santi C. 2014. Organoselenium Chemistry: Between Synthesis and Biochemistry. Bentham Science Publishers,Sharjah, United Arab Emirates.

Sele V, Sloth JJ, Lundebye A-K, Larsen EH, Amlund H. Arsenolipids in marine oils and fats: A review of occurrence, chemistry and future research needs. Food Chem, 2012; 133: 618-630.

Sergeiko A, Poroikov VV, Hanus LO, Dembitsky VM. Cyclobutane-containing alkaloids: origin, synthesis, and biological activities. Open Med Chem J 2008; 2: 26-37.

Simon C.2014. Réactivité des cycles tendus du silicium vis-àvis des métaux de transitions: un accès rapide à des drogues silylées polycycliques. Thesis, Université Pierre et Marie Curie, Paris, France.

Thackray A, Sturchio JL, Carroll PT, Bud RF. 1985. Chemistry in America 1876-1976: Historical Indicators (Chemists and Chemistry). Springer, Germany.

Terent'ev AO, Platonov MM, Levitsky DO, Dembitsky VM. Organosilicon and organogermanium peroxides: synthesis and reactions. Russ Chem Rev, 2011; 80: 807-828.

Terry N, Zayed AM, De Souza MP, Tarun AS. Selenium in higher plants. Annu Rev Plant Physiol Plant Mol Biol, 2000; 51:401-432.

Valitova JN, Sulkarnayeva AG, Minibayeva FV. Plant sterols: diversity, biosynthesis, and physiological functions. Biochemistry (Moscow), 2016; 81: 819-834.

Visser GWM, Diemer EL, Kaspersen FM. The preparation of aromatic astatine compounds through aromatic mercury compounds part II: Astatination of pyrimidines and steroids. J Label Compd Radiopharm, 1981; 18: 799-807.

Wirth T. 2011. Organoselenium Chemistry: Synthesis and Reactions. John Wiley \& Sons, Inc., Germany.

$\mathrm{Yu} \mathrm{X}$, Xiong $\mathrm{C}$, Jensen KB, Glabonjat RA, Francesconi KA.Mono-acyl arsenosugar phospholipids in the edible brown alga Kombu (Saccharina japonica). Food Chem, 2018; 240: 817-821.

Xu R, Fazio GC, Matsuda SP. On the origins of triterpenoid skeletal diversity. Phytochemistry, 2004; 65(3):261-291.

Zubair MS, Al-Footy KO, Ayyad SE, Al-Lihaibi SS, Alarif WM.A review of steroids from Sarcophyton species. Nat Prod Res, 2016; 30: 869-879.

\section{How to cite this article:}

Dembitsky VM, Gloriozova TA, Poroikov VV. Biological Activities of Organometalloid (As, At, B, Ge, Si, Se, Te) Steroids. J App Pharm Sci, 2017; 7 (11): 184-202. 